\title{
AS TECNOLOGIAS DA INFORMAÇÃO E DA COMUNICAÇÃO COMO MEDIADORAS NO PROCESSO DE FORMAÇÃO DOCENTE:UM RECORTE NOS GRUPOS DE TRABALHO DA ANPED - 2009 A 2012
}

\author{
Carla Spagnolo ${ }^{1}$ \\ Ana Margô Mantovani ${ }^{2}$ \\ Bettina Steren Santos ${ }^{3}$ \\ César Augusto Müller ${ }^{4}$
}

\section{Resumo}

Este texto apresenta uma reflexão acerca da formação do educador, mediada pelo uso das Tecnologias da Informação e da Comunicação (TIC's), com enfoque nas discussões realizadas nas reuniões anuais da Associação Nacional de Pós-Graduação e Pesquisa em Educação (ANPED). Para tal, buscou-se evidenciar como as TIC's são contempladas nos Grupos de Trabalho Formação de Educadores (GT8), Currículo (GT12) e Educação, Comunicação e Tecnologia (GT 16), entre a 32a e 35 reuniões (2009 a 2012). A partir de um recorte desses trabalhos, constata-se que a disseminação do uso das TIC's encontra maior concentração no GT16, que focaliza a importância da formação docente para a apropriação das TIC's no processo de aprender e ensinar. Entende-se que a vivência de experiências de aprendizagem com o uso das TIC's, no processo de formação do educador, é uma condição necessária para que este desenvolva competências e habilidades que permitam construir práticas pedagógicas em congruência com estas tecnologias.

\footnotetext{
${ }^{1}$ Doutoranda do Programa de Pós-Graduação em Educação, (PUCRS). Bolsista Integral Capes. Endereço:Rua Visconde de Pelotas, 172, Fagundes Varela, RS. Telefone: 54-99178032. E-mail: caispa@ hotmail.com

2 Doutoranda do Programa de Pós-Graduação em Educação, (PUCRS). Bolsista Parcial Capes. Docente do Programa de Pós-Graduação em Memória Social e Bens Culturais do Centro Universitário La Salle (UNILASALLE). Endereço: Avenida Victor Barreto, 2288, Canoas, RS, Brasil. Telefone: 3476 8558. E-mail: margo@unilasalle.edu.br

${ }^{3}$ Pós-doutorado no College of Education, The Univesity of Texas at Austin, EUA, Doutora em Psicologia Evolutiva e da Educação - Universidad de Barcelona. Coordenadora do Grupo de Pesquisa "Processos Motivacionais em Contextos Educativos" Professora do PPGEDU da FACED/PUCRS. Endereço: Av. Ipiranga, 6681, Predio 15, sala 380. Porto Alegre - RS, Brasil.=. Telefone:51- 3320 3620. E-mail: bettina@ pucrs.br ${ }^{4}$ Doutorando do Programa de Pós-Graduação em Educação, (PUCRS). Bolsista Parcial Capes. Rua Marechal Deodoro, 640, Santa Cruz do Sul, RS Brasil.. Telefone 51-99414844. E-mail: cesar@unisc.br
} 
Palavras-chaves: Formação Docente, TIC's, ANPED

\section{INTRODUÇÃO}

De acordo com Tornero e Varis (2012), os atuais avanços das tecnologias da informação na difusão dos novos meios digitais determinam a crescente importância da alfabetização midiática que, segundo os autores, é uma competência básica que serve de suporte para demais competências, tais como competências didático-pedagógicas e tecnológico-digitais. Apontam os autores que a alfabetização midiática é reconhecida quase universalmente como uma das competências chaves para efetivamente acompanhar e propor mudanças nos sistemas educativos da sociedade contemporânea.

Nesse sentido, para fazer uma reflexão acerca dos processos formativos na contemporaneidade, caracterizada pela cultura digital, é preciso pensar a respeito do uso e apropriação das TIC's e de que forma essas tecnologias estão sendo contempladas, tanto no contexto formativo do futuro educador quanto nos contextos onde ele exercerá a docência. Por isto, para pautar a reflexão aqui apresentada, é imprescindível tecer algumas considerações com enfoque nos trabalhos apresentados em reuniões da Anped, no período de 2009 a 2012, a respeito do uso das TIC's no processo de ensino e aprendizagem. Na procura de chaves teóricas que subsidiem a expansão tecnológica e sua aceitação nos ambientes escolares, urge destacar, qual é o significado da palavra tecnologia. De acordo com o dicionário Michaelis (2012), tecnologia é um termo que envolve o conhecimento técnico e científico e as ferramentas, processos e materiais criados e/ou utilizados a partir de tal conhecimento. Linguagem peculiar a um ramo determinado do conhecimento, teórico ou prático.

Bertrand (2001), ao estudar as teorias contemporâneas da educação, apresenta uma classificação das teorias, realizada em função de quatro elementos polarizadores das reflexões sobre a educação: o sujeito (estudante); os conteúdos (matérias, disciplinas); a sociedade (os outros, o mundo, o meio, o Universo); e as interações pedagógicas entre estes três polos (o docente e as tecnologias de comunicação). Dentre a classificação das teorias, aponta as “Teorias Tecnológicas” também denominadas Tecnosistêmicas ou Sistêmicas. Nessas teorias, 
as tecnologias são entendidas como procedimentos de ensino e como material didático que utiliza comunicação e tratamento da informação, tais como: computador, televisão, vídeo, hipermídia, etc.. Então, é o conjunto dos suportes para a ação, resultando todos da aplicação sistemática de conhecimentos científicos e com o objetivo de resolver problemas práticos.

As teorias tecnológicas assentam no fato de, após o impulso tecnológico do século XX, ser necessário melhorar a tecnologia dos processos de comunicação pedagógica com o objetivo de aperfeiçoar a aprendizagem. Apresentam duas grandes tendências: a Teoria Sistêmica- consiste em examinar as relações entre os elementos em função das finalidades visadas; e a Teoria Hipermidiática- consiste em examinar os ambientes tecnológicos na perspectiva da sua interatividade. Como representantes citam-se: Morin que popularizou a Teoria Sistêmica; Skinner e sua teoria comportamentalista, criador de tecnologias como Instrução Programada e Máquinas de Ensinar, durante os anos 50. Em outro enfoque, encontra-se Seymour Papert (MIT), discípulo de Piaget, criador da Filosofia e Linguagem Logo de programação e do construcionismo. Papert, no início dos anos 80, iniciou e abriu caminho para as pesquisas sobre a criação de ambientes abertos e informatizados de aprendizagem (MANTOVANI, 2012).

Considera-se importante esta contextualização das teorias tecnológicas, uma vez que representam concepções epistemológicas que estão presentes no uso das TIC's no contexto educacional e que permeiam os processos formativos e as práticas didático-pedagógicas dos educadores. De acordo com Schlemmer e Backes (2008, p.530), “[...] o que faz com que um processo de ensino e de aprendizagem seja eficiente não é a opção tecnológica, mas sim a proposta epistemológica-didático-pedagógica que suporta o uso de determinada tecnologia".

$\mathrm{Na}$ educação, a tecnologia continua causando impacto e produzindo alterações no cotidiano da vida escolar. As mudanças sociais aceleradas e os avanços cada vez mais rápidos e eficazes das TIC's criam de certa forma um distanciamento entre a realidade dos alunos nascidos na era digital e a insegurança dos educadores, imigrantes digitais, em trabalhar com o novo. Nesse sentido, Prensky (2010) destaca que as habilidades de atenção e concentração dos alunos de hoje mudaram, sendo que a atenção é canalizada para interesses pessoais e do seu grupo de referência (geralmente virtual). Os alunos se mantêm conectados durante 24 horas, todos os dias, portanto se comportam, pensam e aprendem de uma forma diferenciada das gerações anteriores. 
Assim, as TIC’s estão cada vez mais disponíveis, fazendo parte da realidade dos alunos, enquanto os educadores, em sua maioria, provenientes de uma sociedade analógica, vivem o paradoxo de ensinar de uma forma que não foram ensinados. Então, o crescente avanço científico e tecnológico introduz novas demandas sociais e educacionais, exigindo do educador um perfil que nem sempre possui devido, muitas vezes, à precariedade de sua formação profissional. Por isso, é necessário pensar na melhoria e na qualificação dos processos e práticas direcionadas à formação do futuro educador, na perspectiva da cultura digital.

No entanto, ainda encontramos um cenário educacional, muitas vezes distanciado do uso das TIC's, sendo que estas deveriam ser utilizadas para estabelecer redes de conexões de pesquisa e conhecimento, de interação e imersão em ambientes de aprendizagem. Construir modos criativos e significativos de apropriação dessas tecnologias é desafio que os educadores precisam incorporar em seu fazer pedagógico. Repensar e incorporar as transformações da contemporaneidade, levando em consideração mudanças necessárias no currículo escolar, é uma forma de aproximar a prática docente a um caminhar unificado com o mundo e a realidade social. Isto implica em repensar concepções acerca de educar, ensinar e aprender, ou seja, implica em um redimensionamento da prática educacional.

\section{CONTEXTO DO ESTUDO: RECORTES DO USO DAS TIC'S EXTRAIIDOS DOS GRUPOS DE}

\section{TRABALHOS DA ANPED}

O objetivo desse estudo é fazer uma reflexão sobre a formação do educador na Educação Básica, mediada pelo uso das TIC's para qualificação da prática pedagógica, tendo como foco as discussões realizadas nas reuniões anuais da Anped, entre a $32^{a}$ e $35^{a}$ reuniões no período de 2009 a 2012. O propósito de efetivar o estudo neste período deve-se ao fato de já existirem trabalhos publicados nas reuniões da Anped, sobre o estado da arte do referido assunto, até o ano de 2008, como por exemplo, o trabalho realizado por Santos (2010), dentre outros. Como não se encontrou referências a esta temática no período posterior, optou-se em realizar esse estudo a partir de 2009.

Nessa perspectiva, buscou-se evidenciar como as TIC's são contempladas nos Grupos de Trabalho Formação de Educadores (GT8), Currículo (GT12) e Educação, Comunicação e 
Tecnologia (GT 16) no período referido. Para tal, elaborou-se uma revisão bibliográfica envolvendo esses grupos, buscando-se identificar trabalhos que tratam da incorporação das TIC's no processo de ensino e aprendizagem referente à educação básica e de que forma os educadores estão se apropriando dessas tecnologias em suas práticas educativas. Por meio de uma varredura de artigos nos GT referidos, a respeito do uso das TIC's na educação básica, efetivou-se uma consulta permeando por todos os artigos dos três grupos de trabalhos das últimas quatro reuniões, elencando todos os trabalhos por meio de uma tabela caracterizada por título, autor, resumo e metodologia. Encontrou-se 18 artigos abordando o tema, sendo que desses, três artigos encontram-se no GT Formação de Educadores, dois no GT Currículo e 13 no GT Educação e Comunicação.

Dentre esses artigos, encontraram-se temáticas específicas que, para fins da reflexão aqui apresentada, foram definidas como balizadores de análise, no que concretiza a disseminação para o uso das TIC’s na educação básica, a saber: Programas do governo para Inclusão Digital, A formação do educador no contexto da cultura digital, As implicações do uso das TIC's no processo de ensino e aprendizagem e $\mathrm{O}$ olhar do educador sobre as TIC's, que serão descritos nas seções seguintes.

\subsection{Programas do governo para Inclusão Digital}

$\mathrm{Na} 35^{\mathrm{a}}$ reunião, a mais recente até então, ocorrida no ano de 2012, observou-se trabalhos, sobre a temática aqui apresentada, no GT Currículo e GT Educação e Comunicação. Nesse último, foram encontrados trabalhos com especificações acerca de reflexões sobre programas como EDUCOM, Programa de Informática (PROINFO) e Um computador por aluno (UCA), desenvolvidos pelo Ministério da Educação (MEC) com objetivos, a priori, de promover a inclusão digital nos ambientes escolares, incluindo educadores, alunos e toda comunidade escolar.

Linhares e Ferreira (2012) proferem a pesquisa pelo viés das dificuldades docentes para o uso das TIC's, mediante a formação do programa UCA, bem como os impactos, limites e desafios dessa formação e da gestão para implantação do programa. Os autores demonstram inquietação com as práticas educativas que desconsideram outros espaços coletivos como importantes para a construção do conhecimento e potencializadores de novos saberes e aprendizagens. Afirmam que, ao ignorar o papel e a influência das TIC's na formação dos 
sujeitos, a escola mantém a miopia sobre a diversidade das realidades socioculturais e dos novos espaços de aprendizagens que podem ser promovidos pelo uso dessas tecnologias digitais.

$\mathrm{Na}$ sequência, incluído no GT Currículo da 34 ${ }^{\mathrm{a}}$ reunião, Seixas (2011), busca compreender o impacto do projeto "Um Computador Por Aluno" no currículo e prática pedagógica com o artigo "Conectando a rede: recontextualizações do projeto Um computador por Aluno (UCA) em uma escola municipal do Rio de Janeiro". A autora, em seus relatos, enfatiza que artefatos tecnológicos por si só, não garantem a melhoria tão almejada na qualidade da educação, porém, afirma que as práticas docentes podem influenciar novas políticas, produzir outros currículos e recontextualizar diferentes visões e concepções. Isso significa que ainda “[...] existem muitos links a serem feitos.” (p.11).

Na mesma reunião dentro do GT Educação e Comunicação, Santos (2011) levanta questões sobre as rápidas mudanças sociais provocadas pelos avanços tecnológicos e suas influências nos ambientes educacionais:

\footnotetext{
No âmbito da educação escolar, surge um grande desafio que é formar o cidadão capaz de situar-se criticamente, de autorrealizar-se, de "aprender a aprender" e de estar inserido na sociedade em meio a transformações vertiginosas. [...] É nesse cenário, comumente chamado da "sociedade da informação", que diferentes linguagens e culturas ambivalentes se entrelaçam e estão presentes na sala de aula, exigindo de seus principais atores, alunos e professores, a aquisição de novas práticas educativas. (SANTOS, 2011, p. 01).
}

Analisando o contexto atual, é perceptível a necessidade da qualificação dos educadores, rumo à construção de novos conhecimentos e atualização para a apreensão e apropriação tecnológica. Para a autora referida, o educador, como agente mediador entre a escola e a sociedade, deve se sentir desafiado a buscar esses saberes. Usar a tecnologia como um recurso para seu fazer pedagógico, deve fazer parte do planejamento, para que sua atuação aconteça de forma significativa.

$\mathrm{Na} 33^{\mathrm{a}}$ Reunião, observa-se uma tendência maior para o ensino superior e publicações reduzidas sobre a formação de educadores para o uso das TIC's na Educação Básica. Aqui cabe ressaltar no GT Educação e Comunicação, o trabalho de Fantin e Rivotella (2010), que discutem o uso das mídias e consumos culturais de educadores. Expõe que as mídias digitais guiam uma transformação gradual do perfil do usuário de espectador ao de produtor. "Na internet podemos abrir e gerir um blog com relativa facilidade, comunicar com MSN ou com 
Skype; com o celular podemos fotografar, gravar e enviar fotografias e vídeos, e salvar no computador." (p.03).

Porém, existe a discussão, sobre os educadores de escolas de educação básica no sentido de não possuir um bom capital cultural, por estarem distantes das potencialidades que as TIC's oferecem. Nesse estudo, os autores propõem alguns resultados que desmistificam esse conceito generalizado.

Evidencia-se uma transformação dos hábitos e das práticas culturais em ambientes de alta densidade tecnológica fazendo com que haja uma interação cada vez maior dos professores com as tecnologias. É possível inferir que a incorporação de novos hábitos de consumo midiático pelos professores possa repercutir positivamente no fazer docente. (FANTIN e RIVOLTELLA 2010, p.13).

No ano anterior, na $32^{\mathrm{a}}$ reunião da Anped, há achados com olhar histórico-reflexivo sobre a formação dos educadores para o uso das TIC's, bem como o uso de tecnologias como o blog e a importância dessas tecnologias para um processo de ensino e aprendizagem criativo e singular.

Constatou-se, por meio dos títulos dos artigos apresentados na $35^{\mathrm{a}}$ reunião da Anped, realizada em 2012, uma maior preocupação com a disseminação das TIC's para docentes e discentes da Educação Básica (Ensino Fundamental e Médio). Muitos dos trabalhos, principalmente no GT Educação, Comunicação e Tecnologias, trazem como tema, o uso das TIC's como meio de facilitar o processo de ensino e aprendizagem. Também, são retratadas as benesses, que permeiam pela amplitude de inúmeras possibilidades referentes à mobilidade dos aparelhos tecnológicos, que podem dissolver os limites e fronteiras da sala de aula. A partir desse pressuposto, reconfigura-se uma nova lógica da comunicação e da educação em que as práticas advindas da cultura digital tornam-se, teoricamente, mais coletivas. Diante de muitos benefícios existentes, os desafios representam a incorporação e apropriação da cultura digital pela e na escola, que a bem da verdade, já fazem parte das práticas cotidianas das crianças e jovens (FERREIRA, 2012). Para avançar nesse quesito, a formação dos educadores é fundamental para densificar o trabalho pedagógico e a interação dos alunos com as tecnologias digitais.

Trabalhos como dos autores Ferreira e Linhares (2012), trazem a percepção da formação dos educadores para cultura digital como novos modos de percepção, de linguagem e conduzem para uma sensibilização de que a tecnologia, hoje, não pode ser remetida somente para as novidades dos aparatos. Aquém dessa concepção, a formação deve conscientizar os docentes para um novo modo de viver, de se relacionar e de aprender. Ao utilizar as TIC's em 
sala de aula, o educador pode oferecer ações interativas e colaborativas que potencializam a autoria, a criatividade e o conhecimento.

\title{
2.2 A Formação do educador no contexto da cultura digital
}

Considera-se importante destacar as conceituações acerca de formação humana e capacitação que norteiam esse estudo. Conforme, Maturana e Rezepka (2008), a formação humana consiste no desenvolvimento do ser humano como uma pessoa capaz de ser cocriadora de um espaço de convivência social desejável. Para tal, a formação humana como tarefa educacional implica na criação de condições para que o ser humano cresça no autorrespeito e no respeito pelo outro, levando em consideração as individualidades e identidades relacionadas com as construções/significações anteriores do sujeito, ou seja, com sua ontogenia. Os autores apontam ainda que a tarefa da educação é formar seres humanos para o presente, "qualquer presente", por isso o processo de formação precisa estar em congruência com a realidade, com o cotidiano, o viver e conviver das pessoas em sociedade e, neste caso, com a sociedade inserida no contexto da cultura digital.

De acordo com Maturana,

\begin{abstract}
Educar é uma coisa muito simples: é configurar um espaço de convivência desejável para o outro, de forma que eu e o outro possamos fluir no conviver de uma certa maneira particular. Nesse espaço, ambos, educador e aprendiz, vão se transformando de maneira congruente. Espaço no qual se faz e se reflete sobre o fazer. (MATURANA, 1993, p.33).
\end{abstract}

Assim, para ensinar e aprender é preciso viver e conviver com o outro, relacionar-se e estabelecer vínculos de cooperação. E é nesse espaço que se configuram as relações interpessoais fundamentais no processo de construção do conhecimento.

Ainda, para Maturana e Rezepka (2008, p.11), a capacitação "tem a ver com a aquisição de habilidades e capacidades de ação no mundo no qual se vive, como recursos operacionais que a pessoa tem para realizar o que quiser viver". Então, a capacitação consiste em criar espaços de ação para o fazer na reflexão, possibilitando o exercício das habilidades que se deseja desenvolver, é um instrumento e caminho na realização da tarefa educacional. Enquanto a formação é o fundamento de todo processo educativo, preocupando-se com o "ser", a capacitação são as ações planejadas para a realização da tarefa educacional, cuja 
preocupação é o "fazer" e na reflexão que este fazer traz consigo.

Então, para o atendimento das atuais demandas sociais e educacionais da sociedade contemporânea, é imprescindível que o educador se constitua num prático reflexivo (SHÖN, 2007) e esteja aberto a novas aprendizagens, reconstruindo continuamente seus saberes experienciais, articulando-os com pressupostos teóricos que lhe viabilizem refletir e reinventar cotidianamente o seu fazer pedagógico. Nessa perspectiva, Maturana e Rezepka (2008, p. 15) apontam que "as conversações de capacitação entrecruzam-se com as conversações de formação humana", sendo condição para possibilitar a criação de um espaço de conhecimentos reflexivos e capacidade de ação no professor que, por sua vez, possam ser estendidas para seus alunos, em um processo de ampliação contínua de ação e reflexão (MANTOVANI, 2009).

A utilização das TIC's possibilita esses processos necessários para a formação de um educador prático reflexivo que possa perceber a necessidade do uso de tais tecnologias em um novo contexto de aprendizagem no qual o aluno, por meio de sua ação (atividade do sujeito) e interação (meio físico, social e digital virtual) torna-se o autor de sua própria aprendizagem, desenvolvendo habilidades e competências necessárias para participar de forma autônoma desse processo (MANTOVANI, BACKES e SOUZA, 2011).

É conveniente chamar a atenção para os escritos de Santos (2010), quando em seu texto "A formação dos educadores para o uso das tecnologias digitais nos GT's de formação de educadores e educação e comunicação da Anped 2000 a 2008", busca resultados de como esse tema está sendo contemplado nas reuniões. Muitas indagações surgem na medida em que os trabalhos são analisados: "que formação sobre computador/internet dará conta de articular o instrumental e o pedagógico? Será o uso das tecnologias na prática pedagógica uma utopia? O intenso uso das TIC's na educação a distância poderá contribuir para que o aluno utilize tais recursos em sua prática pedagógica?" (p. 11). O autor, ainda, destaca que embora as TIC's façam parte do cotidiano da vida das pessoas, no ambiente escolar, esses saberes ainda passam por um processo lento de efetivação, além de que, a formação dos professores não potencializa a exploração de possibilidades dos recursos tecnológicos para serem incorporados, o que compromete a implementação das tecnologias digitais na prática pedagógica do contexto escolar.

Santos (2010), ao concluir o trabalho referido, destaca que os resultados apontam para caminhos de reformulação das propostas de formação dos educadores para uso das TIC's: 
Nesse debate entendo que a formação do professor é essencialmente um ato político e deve ser reconstruída, considerando o contexto histórico, político e cultural no qual estamos imersos. Como produção cultural, as tecnologias não podem ser excluídas da escola, da formação, da prática docente e das pesquisas. (SANTOS, 2010, p.12)

Não restam dúvidas que o ato de ensinar as novas gerações está imerso em riscos e controvérsias, os quais geram insegurança nos educadores. Marchesi (2008) coloca em questão a desvalorização da competência profissional, do rigor científico e da capacidade dos docentes de enfrentar, com garantias, os problemas existentes, em virtude da banalização da educação frente a observações “[...] de que na educação tudo está em questão e que se pode opinar sobre qualquer coisa." (MARCHESI, 2008, p. 12).

Conforme estudos do autor referido, a estafa profissional começou a ser pesquisada a partir de 1970. Muitos fatores foram identificados sobre ações, reações e sensações dos educadores seguindo a gênese da evolução histórica-social, porém, o autor afirma ainda que é preciso analisar os fatores protetores e dinamizadores da atividade docente que favorecem o bem-estar.

\footnotetext{
Muitos deles não dependem dos professores. Mas há outros, especialmente aqueles relacionados com suas competências e disposições pessoais, que devem ser cuidados tanto pelos próprios professores como pelos responsáveis educacionais: o fortalecimento das competências profissionais, o equilíbrio emocional e o comprometimento moral. (MARCHESI, 2008, p.56).
}

As Diretrizes Curriculares Nacionais destacam a importância do papel do educador no processo de aprendizagem do aluno, tendo como marco político-institucional os anos 80 com o processo de construção das Leis de Diretrizes e Bases da Educação Nacional (LDBEN), a qual preconiza iniciativas inovadoras sintonizando as instituições de ensino com as formas contemporâneas de conviver e de ser.

Em alguns momentos a prática diverge da teoria e na medida em que burocraticamente a legislação defende condições favoráveis ao trabalho do educador, na realidade muitas instituições não garantem qualidade para efetivar o verdadeiro papel do educador que não é mais o de transmitir informações, mas sim mediar e proporcionar situações problemas, para desenvolver habilidades e capacidades de pensar, refletir e construir o conhecimento. 
A busca pelo bem-estar docente passa pela melhoria nas condições de trabalho e inclusive pela melhoria do contexto social. O educador precisa sentir-se incentivado e assegurado por toda a comunidade escolar.

É também essencial dar a conhecer e sensibilizar os encarregados de educação para
o trabalho do professor no sentido da cooperação entre pais e professores e
estratégias educativas condizentes e consoantes nos dos ambientes de educação e
desenvolvimento, a escola e a família. É ainda necessário dar aos professores
condições de trabalho que possam permitir concretizar a sua competência
profissional e realizar um trabalho de qualidade. (JESUS, 2007, p. 65).

Desse modo, conforme as ideias do autor referido, a formação dos educadores deve ser contínua e sua prática acompanhada e apoiada por todas as partes envolvidas com a educação para que justamente a prática educativa possa adequar-se à realidade atual, caraterizada pela cultura digital. Oferecer oportunidades para a cooperação entre educadores, e educadores com pais, no sentido da resolução de problemas comuns, perspectivas futuras de educação e do fornecimento de apoio mútuo, podem ser alternativas que facilitam a busca pela eficiência no processo de ensino e aprendizagem, e a ruptura da resistência e mal-estar a respeito do uso das TIC's na educação. Por isso, o ensinar deve ser algo desenvolvido, pensado e construído por todos os envolvidos com a educação, significando cooperação, coletividade e união.

Observa-se que nos últimos anos tem aumentado significativamente os cursos de formação continuada de professores para a educação básica. Instituições formadoras, públicas e privadas, se envolvem no oferecimento desses cursos para as diferentes redes públicas de ensino, inclusive na modalidade a distância. É de se refletir se isso se deve apenas aos professores que foram formados anteriormente ou se os cursos de formação inicial estão preparados para formar profissionais capazes de lidar com as tecnologias atuais e futuras. Assim, a educação continuada apresenta-se como uma alternativa para suprir as lacunas decorrentes da formação inicial no que tange à capacitação do futuro educador para o uso crítico e criativo das TIC’s no processo de ensino e aprendizagem. Então, a necessidade da educação continuada para educadores, é emergente, principalmente quando lembramos que as tecnologias estão inseridas nas salas de aula, e os alunos que chegam à escola, nascidos na era digital, precisam da conectividade da realidade entre escola e cotidiano.

De acordo com Palfrey (2011, p. 268): "Para as escolas se adaptarem aos hábitos dos Nativos Digitais e à maneira como eles estão processando as informações, os educadores 
precisam aceitar que a maneira de aprender está mudando rapidamente." Nesse contexto, torna-se imprescindível repensar os processos de formação docente ancorados pela utilização das TIC's, problematizando continuamente suas possibilidades pedagógicas e limitações. Em trabalho publicado na $34^{\mathrm{a}}$ reunião da Anped no GT Educação, Comunicação e Tecnologias, Santos enfatiza o papel do educador como formador, no sentido de ampliar sua própria formação para a inserção no mundo tecnológico:

\footnotetext{
Assim, o professor, como agente mediador entre a escola e a sociedade, deve se sentir desafiado a envidar esforços no propósito de cuidar de sua formação nesse campo do saber. Usar a tecnologia como ferramenta do labor docente deve se constituir em meta, com vistas à formação crítica do estudante, para que sua atuação aconteça de forma produtiva e significativa, no bojo da diversidade que marca a sociedade. (SANTOS, 2011, p.1-2).
}

Assim, a prática docente não pode estar dissociada da educação continuada e permanente dos educadores que necessitam acompanhar as transformações da sociedade contemporânea e possibilitar a discussão da realidade em que o sujeito está inserido.

\subsection{As implicações do uso das TIC's no processo de ensino e aprendizagem}

Como referido anteriormente, o avanço tecnológico do século XX marcou as instituições escolares. A introdução do computador na educação tem provocado uma verdadeira revolução na nossa concepção de ensinar e de aprender. O contato com a tecnologia, nos ambientes educacionais, ocorre tanto para facilitar a realização de atividade rotineiras da sala de aula, bem como para a elaboração de atividades mais criativas. Porém, sabe-se que o domínio da técnica por si só, não garante a utilização das tecnologias de forma realmente inovadora.

Por isso, os ambientes educacionais devem repensar sobre seus fundamentos e permitir cada vez mais novas descobertas, superar a fragmentação do ensino, acolher o digital e a rede, desfrutando da atual situação que estamos vivendo. Nesse âmbito da educação escolar, surge um grande desafio que é formar o cidadão capaz de situar-se criticamente, de "aprender a aprender" e de estar inserido na sociedade em meio a transformações pretenciosas. Neste sentido, atribui-se ao papel da escola assegurar condições para que crianças e jovens se adaptem às novas formas de organização. 
A partir de 1990, podemos perceber um acentuado movimento de reformas, rumo ao avanço da incorporação das TIC's na sociedade. Para Palfrey e Gasser (2011), desde o início da década de 1970 o mundo começou a mudar, e depressa. Através de troca de documentos e mensagens com uso de linhas telefônicas e as primeiras máquinas consideradas computadores. Mais tarde, ainda na década de 80 começou a entrar o uso popular do e-mail e na sequencia, em 1991, a World Wibe Web $(W W W)$ ingressou fortemente como "mecanismo de busca". No entanto, de acordo com os autores, foi no ano de 2008 o período de transformação mais rápida, no que se refere à tecnologia de informação.

Dessa forma, nenhum aspecto da vida moderna fica intocado pela maneira em que muitos de nós hoje em dia usamos as tecnologias: "O mais incrível, no entanto, é a maneira em que a era digital transformou o modo como as pessoas vivem e se relacionam umas com as outras e com o mundo que as cerca.” (PALFREY e GASSER, 2011, p. 13).

É notório que o processo de ensino e aprendizagem, com base nessas convicções, desenvolve-se em um novo contexto, em uma nova realidade social que não há como evitar.

Trata-se, portanto de ir reconstruindo nossa visão da realidade, os discursos que mantemos para compreender o papel da educação e das escolas, seus fins, na nova situação e os procedimentos de ensinar e aprender que são possíveis. Ou seja, é preciso elaborar uma nova narrativa, voltada a escrever o discurso acerca da educação; em suma, à luz de novas condições na sociedade em que nos cabe viver. (SACRISTÁN, 2007, p. 41).

A Lei de Diretrizes e Bases da Educação (LDB n. 9394/96) estabelece que o currículo do Ensino Fundamental e Médio deve propiciar ao aluno a compreensão dos fundamentos científico-tecnológicos dos processos produtivos, relacionando a teoria com a prática, no ensino de cada disciplina (BRASIL, 2008). Isto vem reafirmar a importância da escola preparar o aluno para "lidar com as inovações e as transformações sucessivas dos conhecimentos em todas as áreas" (KENSKI, 2007, p.4). Entendemos que, um dos caminhos possíveis, é a inserção das TIC's no contex to educacional.

Pelos diferentes programas criados pelo governo, tais como PROINFO e UCA, percebe-se a preocupação do governo com a inserção das TIC's nas escolas. No entanto, para que essas iniciativas sejam válidas, é preciso que os recursos disponibilizados sejam utilizados. E para que isso aconteça é fundamental pensar na formação e capacitação dos educadores para o uso das TIC's como mediadoras dos processos de ensinar e aprender. 
Para fazer uma reflexão a respeito da apropriação tecnológica, é preciso pensar no desenvolvimento e ampliação de conceitos em âmbito de pesquisa, autoria, envolvimento e avaliação contínua do fazer pedagógico. Desse modo, o educador é considerado a peça chave na receptividade e adesão das TIC’s na sala de aula. Para isso ele precisa assumir um papel prático e de reflexão sobre o trabalho que desenvolve. Esse entendimento possibilita repensar e reinventar a prática pedagógica, desmistificando o conceito do educador como detentor do conhecimento e abrindo espaço para as inovações e novas aprendizagens em colaboração e cocriação com os alunos.

Nessa perspectiva, Santos (2009), em estudo aos GT da Anped de 2000 a 2008, sobre a formação de educadores para o uso das TIC's, enfatiza as possibilidades de apropriação dessas tecnologias pela força e desejo de mudança, pela aceitação e inquietudes de uma prática instável e, principalmente, pela atitude de coragem do docente em admitir o uso das tecnologias também para a construção da subjetividade e para a reconstrução da prática.

O educador exerce atos políticos em virtude das escolhas que realiza no cotidiano escolar, em específico dentro da sala de aula, então é o educador que conduz metodologicamente os procedimentos para a efetivação do ensino e da aprendizagem. Para tanto, é indiscutível que o seu fazer está diretamente ligado com o seu pensar e com a maneira de ser como pessoa. Assim, percebe-se que a aceitação do uso das TICs na educação é resultado da consolidação do mundo digital no seu próprio viver e conviver no cotidiano.

\subsection{O olhar do educador sobre as TIC's}

"O futuro indeterminado que é o nosso neste fim do século XX deve ser enfrentado de olhos abertos." (LÉVY, 1993, p. 196). O autor é pontual em tratar de novas maneiras de pensar e conviver que estão sendo elaboradas no mundo da tecnologia (telecomunicações e informática). Destaca que emanam reflexões a respeito do campo de novas tecnologias intelectuais, abertas, conflituosas e parcialmente indeterminadas, mas suaviza o enfrentamento àqueles que permitem abrir-se para os avanços tecnológicos e mudanças permanentes. É dessa visão que os educadores precisam para adequar-se a realidade atual e apropriar-se das TIC's para melhor aproximação com as demandas sociais e culturais.

Para Liguori (1997), as novas tecnologias informatizadas e o aumento exponencial do conhecimento levaram a uma nova organização de trabalho, onde se faz necessário a 
imprescindível especialização dos saberes, a colaboração interdisciplinar e o fácil acesso à informação. A função da escola passou a ser não mais de transmitir, mas sim (re)construir o conhecimento. O olhar do educador para o processo de ensino e aprendizagem, diante da sociedade contemporânea e tecnológica, sugere a construção de projetos pertinentes que atendam as peculiaridades culturais.

Na pesquisa realizada por Santos, publicada na reunião da Anped em 2011 e intitulada como "Tecnologias e ações de formação na prática docente", a autora relata o pensamento dos docentes sobre o uso das TIC`s. De acordo com os achados, afirma que o emprego das tecnologias pelos educadores ainda está longe de ser uma realidade, necessitando de reorganização do contexto escolar para a aplicabilidade de novas tecnologias no contexto educacional. Parece que em muitos momentos os educadores se opõem ao uso da tecnologia pela falta de condições de "controlar" o uso que os alunos fazem dos equipamentos. Também ficou claro no trabalho, conforme relatos dos educadores, a dificuldade em fazer um planejamento didático-pedagógico mediado pelo uso das TIC's.

Em outro estudo, pertencente a 33 ${ }^{\mathrm{a}}$ Reunião da Anped, Fantin e Rivoltella (2010), expõe a tecnologia vista, sobretudo, como recurso e instrumento útil á própria vida e à profissão. Relata a visão dos educadores pesquisados em palavras como conhecimento, interação, comunicação, rapidez e informação, além das manifestações positivas de docentes diante das mídias e tecnologias.

Na última reunião da Anped (35 $)$, Linhares e Ferreira (2012), relatam na pesquisa com educadores da primeira etapa do Ensino Fundamental da educação básica, que os educadores não acham difícil aprender a usar o computador. No entanto, durante o processo formativo, levantam questões que devem ser consideradas no planejamento dos cursos e programas de formação inicial e continuada uma serie de dificuldades, organizadas em dois grandes blocos: as dificuldades pedagógicas - aulas mais diretas com manuais e "receitas", tempo da formação, desconhecimento sobre a contribuição das tecnologias no processo de ensino e de aprendizagem- e as de gestão das TIC's no espaço escolar - insegurança, problemas com acesso à internet e suporte técnico, inserção das tecnologias no projeto político pedagógico das escolas.

Evidenciam-se divergentes olhares dos educadores a respeito do uso e apropriação das TIC's no cotidiano escolar. É fato inegável que as instituições de ensino têm sido conclamadas à realização de mudanças profundas, mediante ao grande desafio de pensar e 
construir uma nova educação para a sociedade pós-industrial baseada no uso das TIC's. A urgência de novas práticas didático-pedagógicas coloca a escola diante de questões que somente nas últimas duas décadas surgem com maior importância no espaço escolar, a convicção de que as TIC's e suas linguagens, contribuem para a melhoria do processo de construção/apropriação/divulgação do conhecimento e a escola deve estar preparada para conviver, gerenciar e utilizar as TIC's nos processos de ensino e aprendizagem. (LINHARES e FERREIRA, 2012). Então, o papel dos educadores nesse contexto é entrelaçar harmoniosamente as necessidades e complexidades em uma proposta que possa qualificar os procedimentos metodológicos e amenizar o sofrimento pela sensação de ineficácia, aderindo à tecnologia e utilizando-a para facilitar o dia-a-dia.

\section{CONSIDERAÇÕES FINAIS}

Para fazer uma reflexão acerca da formação do educador, mediada pelo uso das TIC's, na sociedade contemporânea, considerou-se relevante evidenciar como tais tecnologias são contempladas nos Grupos de Trabalho (GT8, GT12 GT 16) da Anped, entre a $32^{\mathrm{a}}$ e $35^{\mathrm{a}}$ reuniões realizadas no período de 2009 a 2012. Como a Anped é um espaço de excelência para a pesquisa e discussão de assuntos pertinentes ao contexto educacional, entende-se que o espaço aberto nesses Grupos de Trabalho para a discussão, em especial, sobre a docência, o ensino e a aprendizagem mediados pelo uso das TIC's, contribui de forma significativa para o enfrentamento dos desafios pautados pela cultura digital.

Constatou-se, a partir de um recorte do uso das TIC's extraídos nos GT aqui referidos, que a maioria das instituições de ensino ainda estão construindo seu fazer pedagógico em relação ao uso e apropriação das TIC's em suas práticas educativas. E que este caminho é pautado por dúvidas, incertezas e inquietações, trazendo novos desafios e perspectivas de mudança na compreensão dos processos de ensinar e aprender, mediados pelo uso das TIC's, e na coexistência das gerações analógicas e digitais. Também constatou-se, que a disseminação do uso dessas tecnologias encontra maior concentração no GT16, sendo que esse GT focaliza a importância da formação docente para a apropriação das TIC's nos ambientes educacionais.

Assim, pode-se inferir a necessidade de resgatar o papel e a importância do uso das TIC's nos processos formativos, ampliando a reflexão sobre as concepções epistemológicas 
que estão presentes no uso dessas tecnologias e nas atuais práticas didático-pedagógicas que permeiam o fazer docente nos diferentes espaços de aprendizagem, sejam presenciais ou digitais virtuais.

Nesse sentido é importante destacar que a inovação, no contexto educacional, não está atrelada ao uso de recursos tecnológicos, mas sim à forma de trabalhar. Compete ao educador propor novas metodologias e formas de mediação pedagógica em congruência com as TIC's para que o processo de aprendizagem ocorra satisfatoriamente para o aluno e o próprio educador. Por isso considera-se importante estudos que acenam para a busca de novos paradigmas pautados em concepções metodológicas que permitam o uso crítico e criativo das TIC's, trazendo em seu bojo novas perspectivas para a pesquisa.

\title{
THE INFORMATION TECHNOLOGY AND COMMUNICATION AS MEDIATORS IN THE PROCESS OF TEACHING: A CUT IN WORKING GROUPS OF ANPED - 2009 TO 2012
}

\begin{abstract}
This paper presents a reflection about teacher's formation, mediated by the use of Technology and Communication Information (TCI's), focusing on discussions performed at the annual meetings of the National Association of Graduation Studies and Research in Education (ANPED). So, we were persue to point out how TCI's are included in the Educators Training Working Groups (GT8), Curriculum (GT12) and Education, Communication and Technology (GT 16), between the 32nd and 35th meetings (2009-2012). From a profile of these works, it appears that the widespread use of TCI's is bigger in T16 that focuses the importance of training teachers in the appropriation of TCI's in learning and teaching process. It is understandable that the experience of learning through the use of TCI's in the process of teacher education is a necessary condition for him to develop skills and abilities that allows building of pedagogical practices in congruence with these technologies.
\end{abstract}

Keywords: Teacher's Formation; TCI's; ANPED 


\section{LA TECNOLOGÍA DE LA INFORMACIÓN Y LA COMUNICACIÓN COMO MEDIADORES EN EL PROCESO DE FORMACIÓN DEL EDUCADOR: UN CORTE EN GRUPOS DE TRABAJO DE ANPED - 2009 A 2012}

\section{Resumen}

Este texto presenta una reflexión sobre la formación del educador, mediada por el uso de las Tecnologías de Información y Comunicación (TIC's), focalizando en las discusiones realizadas en las reuniones anuales de la Asociación Nacional de Pós-Graduación e Investigación en Educación (ANPED). Para tal, se buscó evidenciar como las TIC’s son contempladas en los Grupos de Trabajo Formación de Educadores (GT8), Currículo (GT12) y Educación, Comunicación y Tecnología (GT 16), entre la 32 a y 35 a reuniones (2009 a 2012). A partir de un recorte de esos trabajos, se constata que la diseminación del uso de las TIC's se encuentra en mayor concentración en el GT16, que focaliza la importancia de la formación docente para la apropiación de las TIC’s en el proceso de aprender y enseñar. Se entiende que la vivencia de experiencias de aprendizaje con el uso de las TIC's, en el proceso de formación del educador, es una condición necesaria para que este desenvuelva competencias y habilidades que permitan construir prácticas pedagógicas en congruencia con estas tecnologías.

Palabras clave: Formación docente; TIC's; ANPED

\section{REFERÊNCIAS}

BERTRAND, Yves. Teorias Contemporâneas da Educação. Instituto Piaget, $2^{\mathrm{a}}$ edição, Lisboa, 2001.

BRASIL. Lei n ${ }^{\circ}$ 9394/96, de 20 de dezembro de 1996. Estabelece as diretrizes e bases para a educação nacional. Diário Oficial da União. Brasília, 23 dez.1996. Disponível em: http://legislacao.planalto.gov.br/legislacao. Acesso em: maio de 2012.

FERREIRA, Helenice Mirabelli Cassino. Cultura da mobilidade: como ela aparece na escola? $35^{a}$ Reunião Anual da ANPED, Sergipe, 2012. 
GARCÍA, Carlos Marcelo. Formação de educadores: para uma mudança educativa. Porto: Porto Editora, 1999.

JESUS, Saul Neves de. Professor sem stress. Porto Alegre: Mediação Editora, 2007.

JOSSO, Marie-Christine. A experiência de vida e formação. São Paulo: Paulus, 2010.

KENSKI, Vani Moreira. Educação e tecnologias: O novo ritmo da informação. Campinas, São Paulo: Papirus, 2007.

LÉVY, Piérre. As Tecnologias da inteligência: o futuro do pensamento na era da informática. 2. ed. Rio de Janeiro: Editora 34, 1993.

LIGUORI, Laura M. As novas tecnologias da informação e da comunicação no campo dos velhos problemas e desafios educacionais. In Edith Litwin. Tecnologia educacional: política, histórias e propostas. Porto Alegre: Artes Médicas, 1997.

LINHARES, R.N.; FERREIRA, S. L. Reflexões sobre o perfil tecnológico dos professores do núcleo. 35ª Reunião Anual da ANPED, Sergipe, 2012.

MANTOVANI, Ana Margô. O uso das tecnologias digitais virtuais emergentes: contribuições para a constituição do futuro docente no âmbito da formação inicial em cursos de pedagogia e licenciaturas. In: CONGRESSO INTERNACIONAL DE EDUCAÇÃO, VI., 2009. São Leopoldo, RS. Anais... São Leopoldo: UNISINOS, 2009.

MANTOVANI, A. M.; BACKES, L.; SANTOS, B. S. Formação Do Educador No Contexto Da Cibercultura: possibilidades pedagógicas em metaversos (Mundos digitais virtuais em 3 dimensões MDV3D. Revista Contrapontos, Santa Catarina: UNIVALI, v. 12, n.1, jan./abr. 2012. Disponível em: http://www6.univali.br/seer/index.php/rc/article/view/3079. Acesso em: 02 abr. 2014.

MANTOVANI, Ana Margô. Reflexões acerca das teorias contemporâneas da educação. Programa de Pós-graduação em Educação. Pontifícia Universidade Católica do Rio Grande do Sul, 2012.

MARCHESI, Álvaro. O bem-estar dos educadores. Porto Alegre: Artmed, 2008.

MATURANA, H.; REZEPKA, S. N. Formação e capacitação humana. Petrópolis: Vozes, 2008.

MATURANA, Humberto. Uma nova concepção de aprendizagem. Dois Pontos, Belo Horizonte, v. 2, n. 15, p. 28-35, Outono/inverno, 1993.

MORAES, Maria Cândida. As novas tecnologias da informação e Capacitação dos educadores. Washington/DC, 1997.

PALFREY, J.; GASSER, U. Nascidos na era digital: entendendo a primeira geração de nativos digitais. Porto Alegre: Armed, 2011. 
PRENSKY, Marc. Teaching Digital Natives: partnering for real learning. California: Corwin, 2010.

RIVOLTELLA, P. C.; FANTIN, M. Interfaces da docência (des) conectada: usos das mídias e consumos culturais de educadores. 33 ${ }^{a}$ Reunião Anual da ANPED, 2010.

SACRISTÁN, José Gimeno. A educação que ainda é possível: ensaios sobre uma cultura para a educação. Porto Alegre: Artmed, 2007.

SANTOS, Solange Mary Moreira. Tecnologias e ações de formação na prática. $34^{a}$ Reunião Anual da ANPED, Porto de Galinhas, 2011.

SANTOS, Ezicléia Tavares. A formação dos educadores para o uso das tecnologias digitais nos GTS formação de porfessores e educaçãoe comunicação da ANPED - 2000 a 2008. $32^{a}$ Reunião Anual da ANPED, 2009.

SEIXAS, Luciana Velloso da Silva. Conectando a rede: recontextualizações do projeto "Um computador por aluno" (UCA) em uma escola municipal do Rio de Janeiro. $34^{a}$ Reunião Anual da ANPED, Porto de Galinhas, 2011.

SCHLEMMER, E.; BACKES, L.. Metaversos: novos espaços para construção do conhecimento. Revista Diálogo Educacional, Curitiba: PUCPR, v.8, n. 24, mai./ago. 2008. Disponível em: http://www2.pucpr.br/reol/index.php/DIALOGO?dd1=2038\&dd99=view. Acesso em: 02 abr. 2014.

TORNERO, J. M. P.; VARIS, T.. Alfabetización Mediática Y Nuevo Humanismo. Barcelona: Editorial UOC, 2012. 